\title{
CONTROL SYSTEMS FOR IMPROVEMENT QUALITY OF HUMAN RESOURCES
}

\author{
R. J. Widodo ${ }^{1}$, K.C. Ting ${ }^{2}$ \\ ${ }^{1}$ President of MASDALI/ICSS (Masyarakat Sistem Kendali Indonesia/Indonesian Control \\ Systems Society)rjwidodo@yahoo.com \& masdali@yahoo.com \\ ${ }^{2}$ Department of Agricultural and Biological Engineering, University of Illinois, Urbana- \\ Champaign,USA.kcting@uiuc.edu
}

\begin{abstract}
This paper presents Control Systems (CS) to support the Programs of Education \& Training (E \& T), Research \& Development (R \& D) for improvement quality of Human Resources (IQHR).

The programs of the IQHR must be related with the modern Art, Science, Engineering and Technology (ASET). The prosperity of the Human Resources will be approached from prosperity approach which is mainly emphasized with three universes of aspects: Physical, Intellectual, Emotional and Spiritual (PIES) aspects. There are three basic requirements for developing the Physical aspect: Material, Energy and Information (MEI). Social welfare and increase of life quality are desired output that must be attained from the MEI aspects. Current standard of living of human being should be reported as feedback information in the programs of the IQHR. In global communication, developed countries and developing countries should build several attractive and sound symbiosis bridges, to prevent loss of universe balances. High quality of human resources as products of IQHR activities, have social impacts not only in developed countries but also in developing countries. A new work force strategy without denying the existing of high quality of human resources is established by retooling the work forces, thus the challenges of social impacts should be answered wisely and would be bright opportunities to improve human standards of living.
\end{abstract}

Keywords: CS, E\&T, R\&D, ASET, PIES, IQHR, MEI, human standards of living, social impacts, work force.

Please use the following format when citing this chapter:

Widodo, R.J. and Ting, K.C., 2009, in IFIP International Federation for Information Processing, Volume 295, Computer and Computing Technologies in Agriculture II, Volume 3, eds. D. Li, Z. Chunjiang, (Boston: Springer), pp. 1807-1815. 


\section{INTRODUCTION}

The development of Control Systems (CS) to support Programs of the IQHR represents forces that strongly affect man, life, and civilization. It means that those can be good and can also be evil. The goodness or evil is determined by the purpose and utilization.

The purpose of CS is to support the programs of the IQHR efforts, thus they constitute parts of the development while they also can be the driving force for speeding up development.

The objectives of the programs of the IQHR are to increase the quality of human life. Sustainable development must be supported by health economics. In an expose on health economics, the heath industries are highly laborintensive. Therefore the development is closely tied with the redistribution of income seen from two different aspects, namely with regard to equitable distribution of the results of development, and with the expansion of employment opportunities. These cannot be separated from the programs of the IQHR particularly in the rural area. In this connection, one should keep in mind that in developing CS to support the programs of the IQHR, one must pay heed to the local condition, such as tradition, customs and usages, standard of ASET and quality of infrastructure.

It is now generally accepted that the principle of the appropriate ASET comprises:

1. Low-cost, in proportion with the income level of the local population.

2. Providing job opportunities.

3. The tools and equipment used must be only a few and simple maintenance.

4. The equipment and material should be locally available or only small quantities need to be imported.

5. In harmony with the local socio-cultural conditions.

6. Not needing any intricate infrastructure.

7. A high added value compared with ASET being applied.

The increase of added value shall be achieved through application of ASET in the widest sense. ASET developed must be adapted to social conditions, natural resources and environment.

The main constraint of ASET development in developing countries is the fund, material and manpower. In this connection, it will be necessary to adapt the existing ASET and bring them into harmony with the local conditions. That is why it is necessary to emphasize the main managerial aspect that must cover ASET for existing tradition, customs, and desires of community with regard to the local skills. 


\section{IMPROVING THE QUALITY OF HUMAN RESOUCES (IQHR)}

There are two approaches that must be considered in the IQHR namely: 1 . Prosperity and 2. Security.

The prosperity approach will be mainly discussed in this paper. There are three aspects that must be accounted for. They are Physical, Intellectual, Emotional and Spiritual (PIES) aspects.

The basic need for the physical aspect are MEI:

1. Material,

2. Energy,

3. Information.

The Subsystems of the Social System are:

1. Demography (human resources),

2. Natural Resources,

3. Art, Science, Engineering and Technology (ASET),

4. Law and order,

5. Infrastructure.

The IQHR should be related with:

1. Education \& Training (E\&T),

2. Research and Development (R\&D,

3. Industry and Manufacturing,

4. Implementation and Application of ASET,

5. Repair, Maintenance, and Rehabilitation.

The programs of E\&T and R\&D in developed countries are needed for innovation of new ASET, but in general, in developing countries they are for importation and utilization of ASET only.

\subsection{Basic Requirements and Development}

\subsubsection{Considerations.}

The first human basic need is material: food, clothing, housing, health, and education. We need to greatly increase the productivity of food production. We need to use the latest and modern ASET for modern production, so that marketable surplus far exceeds the amounts by farmers, for their own consumption and production.

The second large area for further investment in ASET infrastructure, namely for energy, information, infrastructure development and natural resources utilization.

In industrial R\&D, for development and expansion of ASET facilities, efforts are being made to make the industrial ASET appropriate solutions to 
the various problems. The needs for communication and transportation infrastructure includes sea, air and transportations, while postal and telecommunication services and a network of radio and television are also important to be concerned.

To implement of progressive manufacturing plans requires that the industries adopt an active and even aggressive attitude towards the acquisition of ASET. They cannot remain passive and static waiting for ASET to be passed on to them. In order to help develop this dynamics and active posture they must be sustained and supported by ASET institutes, providing ASET services relevant to the production processes. This will become the focus of planned efforts to transfer, adapt and develop ASET appropriate and useful for the creation and expansion of productive processes throughout the nation.

Defense-related ASET is the third area in which additional investments are to be made. The need to strengthen ASET, support national's defense and

security capability is obvious given her strategic location, her abundance of resources and her unique geographic features. One nation must be able to control her area of jurisdiction and defend it against actions endangering her sovereignty, the achievement of objectives for her national development, such as equitable distribution, growth, stability, and the progress of her efforts for nation building. One nation has to be ready to commit resources to utilize defense technologies relevant to the strengthening of her people's defense system adapted to the national cultural, geographic, and ASET conditions.

Lastly, a people committed to transfer, adapt, and further develop even the most modern ASET and apply these in already existing cultural environments must take measures to prevent the application of the new ASET from eroding and destroying those cultural values upon which its national identity rests. As is the case in other societies, a national's identity is exemplified by her own unique way of working and living together and by distinctive ways social order is created and maintained. For some developing countries, they already possess ancient cultures long before she became a modern state. For the purpose of maintaining an orderly-balance between established cultural values and the new values inherent in the modern ASET, in the social sciences, in culture and in it's philosophies of life has been designated as the fifth but perhaps the most important area in which infrastructure is to be strengthened. The development of ASET infrastructure in this area is geared towards the maintenance of the ability of a nation's people to preserve the compatibility of its cultural values with the progress of ASET in the first four areas discussed previously.

To achieve this stage of development, ASET and skills are indispensable. Without ASET, no one country will be able to develop her economic potentiality. 
Successful transfer and development of ASET can only take place through the vehicle of consistently executed realistic and concrete programs of production which incorporate a systematic, step by step increase in the degree of comprehension and mastery of successively the more sophisticated ASET. Only through these kinds of progressive manufacturing plans can a society develop itself into a productive power and hence a credible and respected member of the family of nations existing in the world today and in the future.

\subsection{Policies on ASET}

The policies on ASET shall be directed toward developing national capabilities in ASET as necessary for the national development in accordance with the needs and priorities of national development.

The global policies on ASET can in broad outlines reach their targets, when the definite ASET programs can be implemented according to plan.

However, it will still be necessary to study and formulate the supportive ASET programs, to achieve a convergence between the plans and the results we hope for. Special attention must be given to the following:

1. Inter-institutional coordination and interaction, and particularly the optimal distribution and utilization of the available information on ASET.

2. The provision of funds and of skilled staff in accordance with ASET, whereby the development and participation of the regions in accordance with the development and participation of the regions in accordance with the development conditions must be further increased.

3. Proper inducements and remuneration for ASET staff that show superior performance must be planned and formulated as a policy which shall be increasingly introduced in our society.

4. Supportive policies are also needed to distribute and popularize the modus operandi for ASET transfer from overseas, through involving national manpower and materials, in a programmed, systematic, and effectively phased program.

5. In taking benefit of the foreign ASET capacities through bilateral, regional or multilateral collaboration, a mutually beneficial institutional must be pursued.

6. In determining the objectives of ASET programs, the results and utilization should be institutionalized harmoniously in stages.

This is appropriate, as the development of ASET has been funded from taxes and other government revenues raised by the community, and therefore the interests of the community should be given proper attention.

\section{Relations between industry and university}


Educational and Training (E\&T) purposes, are as follows:

1. Have obtained a firm foundation in ASET basis to their fields.

2. Have begun to acquire a working knowledge of the current ASET in their area of interest.

3. Have begun to understand the diverse nature and history of human societies as well as their literary, philosophical and artistic traditions.

4. Have acquired the skills and motivation for continued self-education.

5. Have had an opportunity to exercise ingenuity and inventiveness on a research project.

6. Have had an opportunity for engineering synthesis on a design project.

7. Have developed oral and written communication skills.

8. Have begun to understand and respect the economic, managerial, political, social and environmental issues the surrounding ASET development.

A good vision for the universities-industries cooperation should have some distinctive features including the followings:

1. Innovative and future-oriented.

2. Utopian enough to lead to a clearly better future for the organization.

3. Fitting in with the organization's culture, values and history.

4. Reaching out for new dimensions.

5. Setting standards of excellence and reflecting high ideals and aspirations.

6. Clarifying purpose and direction, including measurable objectives.

7. Inspiring enthusiasm and encouraging Commitment.

8. Reflecting the uniqueness of the organization, its identity and core competencies.

Industry can get the following advantage from its cooperation with research institutions:

1. A redefinition of industry's role, causing it to be increasingly oriented towards need and demand.

2. Consultation and counseling services on industrial property laws, design and development of products, quality control and suchlike.

3. Testing facilities.

4. Assistance in negotiations with projects and equipment suppliers.

5. Techno-economic forecasting.

6. Exchange of ASET information

7. Establishing communications with the overseas ASET institutions, etc.

The factors, which encourage cooperation between ASET institutions, and industrial world include:

1. The improvement of communication lines, contributing to better harmony between resources and needs.

2. The involvement and responsibility of personnel, supported by a satisfactory remuneration system. 
3. The mobility of personnel between the ASET institutions and the industrial world.

4. The beneficial effect of the development projects.

\subsection{Challenges \& Opportunities of ASET}

\subsubsection{Industrial Robot Case}

In manufacturing plants in several countries, there has been a large-scale increase in the usage of industrial robots, which are programmable machine tools designed in many cases to accomplish arduous or complex tasks. Although there has been some opposition to the fact that robots often replace human labor, the author explains why he believes the trend toward robotics will continue, and on balance, be beneficial to the national economy.

ASET developments of the last decade are likely to have as profound a potential impact on productivity, labor markets, working conditions, and the quality of life in the developed countries as the introduction of robot into workplace. According to this bleak scenario, in time, workers either will have to accept lower wages or increase their output if the wholesale loss of jobs to an army of robots is to be prevented.

This pessimistic viewpoint has little basis in fact. The conclusions can be reached based on four factors:

First, the estimate of the number of jobs that could be performed by is relatively small.

Second, almost all of these workers would be spared forced unemployment because of retraining and in some cases the job attrition that occurs through normal retirement.

Third, total employment is a function of real economic growth: robots can have a positive effect on real economic growth and, therefore, a positive effect on total employment.

Fourth, in 10 years, retraining programs can adequately shift displaced workers to new careers. In fact, the main challenge posed to policymakers by increased use of robots is not unemployment but need for retraining.

History shows that labor-saving techniques have led to improved living standards, higher real wages, and employment growth. In large measure, the robotics revolution is merely a continuation of a centuries-long trend that has resulted in enormous material progress.

New forms of employment can be created to offset any jobs directly lost to robots. Protection from job loss can come through retraining programs. Working condition and job safety will improve as robots take over dangerous and undesirable forms of works. 
Technological advances in computers and microprocessors are increasing the sophistication of robots, giving them some "thinking" capacity that increase potential uses.

The key to usage in such area as office work depends in large part on the ability to develop "intelligent" robots capable of performing tasks that vary somewhat over time. Some industry observers believe breakthroughs may allow for extensive introduction of robotics in non-manufacturing tasks within a few years.

Three important dimension of the growth of robotics are subjects to economic analysis. The first is the determinants of the magnitude of the growth of the robotics industry.

The second is the impact robotics unemployment.

The third is the impact that robots will have on wages, profits and prices.

There are two reasons for the growth in the use of robots, one related primarily to supply and the second primarily to demand.

In the long run, robots will be increasingly utilized because the cost of traditional labor-intensive techniques is rising over time, while the cost of the capital-intensive robotic techniques is falling relative to prices generally. These costs decline because the technological advances in robotics lower the capital costs of robots per unit output.

On the other hand, some government policies may speed robotic introduction. For example, where environmental regulations lower worker productivity or raise capital costs associated with the traditional ASET, the traditional technique cost line will shift upward, advancing the date at which robotic adoption becomes profitable. The actual threshold date will vary with the individual job involved, depending on wage levels of human labor, the capital cost of robots, the number of workers the robot displaces, the impact of robotics on product quality, the nature of union contracts, and other factors previously mentioned.

\subsubsection{Retooling the Work Force.}

Important changes in the composition of the work force have occurred over the past four decades, and, in some opinions, even more massive changes lie ahead as many thousands of low-skill jobs are eliminated while at the same time large numbers of new jobs are created to meet the demands of technological advance. If serious employment displacement effects are to be avoided, development of broad-scale training programs in which the private sector plays a key role, in concert with various governmental bodies, will be required, he explains.

It already is clear that robotics will do for manufacturing what mechanization did for agriculture. The robotics of jobs in basic industries such as automobiles is only foretaste of similar changes likely to occur in virtually every manufacturing industry. 


\section{CONCLUDING REMARKS}

It is concluded that :

1. The development of ASET for the IQHR represents forces that strongly affect man, life, and civilization.

2. With ASET, most countries will be able to develop her economic potentiality.

3. The policies on ASET shall be directed toward developing national capabilities in ASET, as necessary for the national development in accordance with the needs and priorities of national development.

4. The spirit of the cooperation among scientists/academics interuniversities should very high.

5. The exchange programs are very useful for scientists, academics and engineers in order to discuss and share the latest development in ASET.

\section{REFERENCES}

Choate, P. , Retooling The American Work Force, Northeast-Midwest Institute, 1982.

Dato' Lee Yee Cheong, The President of World Federation of Engineering Organizations, Keynote Address : Current Activities of the World Federation of Engineering Organizations, CAFEO-21, Jogjakarta, Indonesia, 22-23 October 2003.

Habibie, B.J., Science, Technology and Nation Building, vol. I, Technology Indonesia \& The Agency for The Assessment and Application of Technology, Jakarta, 1991.

Habibie, B.J., Science, Technology and Nation Building, vol. II, Technology Indonesia \& The Agency for The Assessment and Application of Technology, Jakarta, 1991.

Widodo, R.J, .Automatic Control for Reducing Energy Consumption and Improving Energy Conservation, (CAFEO-10), Manila, Phillipines, 5-6 November 1992.

Widodo, R.J. Control Education at Bandung Insitute of Technology,(CAFEO-11), Singapore, 18-19 November 1993.

Widodo, R.J., Development of Control Applications in Electrical Power Systems ,PSDC'95, Bandung Institute of Technology, Bandung, 14-16 March 1995.

Zuboff, S., Computer-Mediated Work : A New World, The President and Fellows of Harvard College, 1982. 